\title{
First Write like You Speak, Then Write like You Write
}

\author{
COMMUNICATION CORNER
}

\author{
by Philip Yaffe
}

\section{Editor's Introduction}

Each "Communication Corner" essay is self-contained; however, they build on each other. For best results, before reading this essay and doing the exercise, go to the first essay "How an Ugly Duckling Became a Swan," then read each succeeding essay.

In this installment, Philip Yaffe introduces a two-step plan to create well-written text that will not only impress the reader, but also engage the reader to digest and comprehend new ideas or concepts with ease. 


\title{
First Write like You Speak, Then Write like You Write
}

\author{
COMMUNICATION CORNER
}

\section{by Philip Yaffe}

Do you find it easier to say things than to write them? You should, because speaking is only the first step in writing.

I'm not talking about public speaking, just ordinary speaking. For instance, you have an idea for a new product for your company, or a new way for your organization to raise funds. You can easily describe it to a colleague in five minutes, but putting it down on paper as a formal proposal takes hours and hours, and it still never seems to be right.

Why? There are two basic reasons for this.

First, when you are telling the idea to a colleague, the words just flow. If there is something your listener doesn't fully understand, he will either ask a question or indicate his perplexity in some other way, so you can make another attempt at getting your point across. When you write the idea, there is no possibility for such interaction; there is no feedback. You must be certain that what you are saying is clear to the people you are addressing in your text with no opportunity to find out if it really is.

Second, when you speak, any slips or errors you make, if not too dramatic, will be quickly forgotten. The error is there, and then it is gone. As long as the general message gets through without too much fog, your listeners will be satisfied.

However, when you write every word counts. When a reader sees something that doesn't look quite right, he will stop, re-read it, scratch his head, and begin generating doubts. Knowing this is how people read (you do it yourself) you agonize over every word, every sentence, and every paragraph to get it just right.

You are not alone. Renowned newspaper columnist Franklin Adams once observed, "Having imagination, it takes you an hour to write a paragraph that, if you were unimaginative, would take you only a minute. Or you might not write the paragraph at all."

No wonder writing seems brutally hard; it is. There's just no getting away from it. Fortunately, there is a way of getting around it. 
Since speaking is so much easier than writing, why not use this as your starting point? In fact, this is what most good writers do, as part of a strict, two-part plan: 1. first draft, 2. revised draft.

\section{First Draft}

The fundamental purpose of the first draft is to develop the text's basic structure and content.

First, outline the subject in your head or on paper so you have a broad idea of the direction you want to take.

Next, pretend you are explaining the subject to a colleague or friend, and just let the words flow. Write rapidly, paying little or no attention to grammar, vocabulary, transitions, etc. Literally assume you are "speaking with your fingers" and just get on with it.

When you have run out of things to say, go back over the text to be certain it contains everything you intended to put in. Frequently, while "speaking with your fingers," you will discover something about your subject you hadn't expected and will want to include. So research it, write it, and include it.

\section{Revised Draft}

The fundamental purpose of the revised draft is to achieve coherence. This is when you rework your text to ensure that it fully meets the "Three Acid Tests" of effective communication.

1. Clear. Your text actually says what you thought you were saying.

2. Concise. Your text includes only what it is really needed. (Extraneous information, however "interesting" or "entertaining," will compromise clarity, so eliminate it.)

3. Dense. Your text contains sufficient factual information to support your premises, arguments, and conclusions. Generalizations without facts are not persuasive.

(Editor's Note: For working definitions of "clear," "concise," and "dense," refer to Communication Corner No.2 "The Three Acid Tests of Persuasive Writing.")

You can now go on to dealing with grammar, vocabulary, syntax, and the other technical concerns that ensure your well-structured text will also be highly readable.

Since the two drafts have fundamentally different functions, they need to be undertaken with fundamentally different mindsets. It is therefore useful to leave a few hours (or days) between the first draft and the revised draft.

During this so-called "incubation period," your subconscious mind will continue thinking about the text while your conscious mind is focused somewhere else. When you do work on the 
revised draft, you will be more efficient. You will produce a much better text in much less time than if you try to do the two phases simultaneously or one immediately after the other.

Not fully convinced about the importance of first writing like you speak, then writing like you write? Well, let's look at some comments from some of the best in the business.

"The faster I write, the better my output. If I'm going slow, I'm in trouble. It means I'm pushing the words instead of being pulled by them."-Raymond Chandler (crime writer)

"Detail makes the difference between boring and terrific writing. It's the difference between a pencil sketch and a lush oil painting. For a writer, words are your paint. Use all the colors."-Rhys Alexander (novelist)

"I'm not a very good writer, but I'm an excellent re-writer. -James Michener (novelist)

"The time to begin writing an article is when you have finished it to your satisfaction. By that time, you begin to clearly and logically perceive what it is you really want to say."Mark Twain (novelist, essayist)

"Write your first draft with your heart. Re-write it with your head."-Anonymous

\section{Mathematical Magic}

Writing and speaking clearly and concisely is a leitmotiv of the "Communication Corner." Early in the series, I put myself to the test by writing instructions for a self-working card trick without supporting diagrams or photos. Since no one asked for clarification, presumably I succeeded.

If you consider algebraic equations to be "illustrations," below is a somewhat different challenge. However, the objective is the same. And so is the guiding principle. In the words of Robert Louis Stevenson, author of Kidnapped, Treasure Island, and The Strange Case of Dr. Jekyll and Mr. Hyde: "Don't write merely to be understood. Write so that you cannot possibly be misunderstood."

If you can achieve this, you can write anything-and say anything in a speech to the plaudits of you audience.

If you wish to enjoy a hysterically funny pastiche on the difficulties of giving clear, concise instruction, you could do no better than to watch a classic routine by famed Irish comedian Dave Allen titled "Teaching Your Kid Time."

\section{$2=1$ an Algebraic Proof}

Here is an apparent mathematical contradiction. I have shown this to a number of people with mathematical backgrounds. Some see the flaw immediately; some spend weeks before giving up and asking me to explain it. It seems to have something to do with one's basic approach to algebra, as I will explain in the next installment. But first the "proof." 
Start with the simple equation $a=b$. To maintain the equality, a fundamental rule of algebra is whatever we do to the left side of the equation we must also do to the right side.

$$
\mathbf{a}=\mathbf{b}
$$

Multiply both sides by a.

$$
a^{2}=a b
$$

Subtract $b^{2}$ from both sides.

$$
a^{2}-b^{2}=a b-b^{2}
$$

Factor both sides of the equation.

$$
(a+b)(a-b)=b(a-b)
$$

Cancel the common factor $(a-b)$ from both sides of the equation.

$$
(a+b)(a-b)=b(a-b)
$$

Thus, $(\mathbf{a}+\mathbf{b})=\mathbf{b}$.

Remove the parentheses to give $\mathbf{a}+\mathbf{b}=\mathbf{b}$.

Remember the original equation $\mathbf{a}=\mathbf{b}$. Now let's substitute.

Let $\mathbf{a}=\mathbf{1}$. Then $\mathbf{b}=\mathbf{1}$.

Thus, $\mathbf{a}+\mathbf{b}=\mathbf{b}$ gives $\mathbf{1}+\mathbf{1}=\mathbf{1}$, which gives $\mathbf{2}=\mathbf{1}$.

Q.E.D.

HOMEWORK: Retrospective to Communication Corner No. 6

Remember the instructions for the homework in CC6.

The following texts appear to be satisfactorily well written, and they are. However, they could be considerably improved. The problem here is not missing information, but how the information is organized. Re-order the information to boost the impact of the texts. Pay particular attention to using the $Q$ \& $A$ (question and answer) technique to ensure that the text passes the "Stop Reading Test." 


\section{Exercise 1}

[Original]

An on-board tracking device operating via the mobile phone system will make it possible for insurance companies to monitor the driving behavior of their customers.

Stored in the back of the vehicle, the device will record the roads on which the motorist is travelling and the time of the journey, and send the information to the insurance company.

The company will then calculate the insurance premium based on an assessment of the relative risk of crashes on the different roads at different times of the day. Motorists will receive a monthly or quarterly "usage statement", similar to a telephone bill, giving the insurance cost for each journey.

By agreeing to the system, motorists could save hundreds of dollars on their automobile insurance.

Trips on superhighways will cost less per kilometre than on city roads because they have lower crash rates.

[Revision]

Motorists could save hundreds of dollars on their automobile insurance by agreeing to have their driving habits monitored by a satellite-tracking device.

Stored in the back of the vehicle, the device will record the roads on which the motorist is traveling and the time of the journey, and send the information via the mobile phone network to the insurance company.

The company will then calculate the insurance premium based on an assessment of the relative risk of crashes on the different roads at different times of the day. Motorists will receive a monthly or quarterly "usage statement", similar to a telephone bill, giving the insurance cost for each journey.

Trips on superhighways will cost less per kilometer than on city roads because they have lower crash rates.

Note: The revision passes the "Stop Reading Test." People could stop reading after the first paragraph and still have a clear, sharp picture of what the story is about. In the original, they have to read at least through the third paragraph.

The writer clearly put himself into the mind of the reader. The original might have been interesting to a "techno-nerd," whose first interest might be how does this new system work. The revision, which suggests significant reduction in automobile insurance premiums, would 
certainly be of interest to virtually everyone. Who wouldn't want to know how to significantly reduce the cost of driving their car?

\section{Exercise 2}

[Original]

Venezuelan President Hugo Chavez has survived a national vote of confidence in his leadership, winning 58 percent of the vote. His supporters immediately celebrated the victory in a pre-dawn rally by exuberantly chanting, "Chavez isn't leaving!"

Señor Chavez's victory claim was supported by Jimmy Carter, the former U.S. president and head of a team of international observers. Information collected by the team "coincided with the partial results announced this morning by the National Electoral Council," Mr. Carter said.

Opposition leaders quickly denounced the official result as fraudulent and called on their supporters to protest in the streets of Caracas, the capital, and throughout the country.

[Revision]

Venezuelan president Hugo Chavez has survived a national vote of confidence in his leadership, winning 58 percent of the vote. Opposition leaders immediately denounced the result as fraudulent and called for massive street protests in Caracas, the capital, and throughout the country.

Señor Chavez's victory claim was supported by Jimmy Carter, the former U.S. president and head of a team of international observers. Information collected by the team "coincided with the partial results announced this morning by the National Electoral Council," Mr. Carter said.

When the result was announced, the president's supporters immediately celebrated in a predawn rally, frequently punctuated by exuberant chants of "Chavez isn't leaving!"

Note: The revision passes the "Stop Reading Test." People could stop reading after the first paragraph and still have a clear, sharp picture of what the story is about. In the original, they have to read at least through the third paragraph.

Also note the density of the text: 1) 58 percent of the vote, 2) Caracas, the capital, 3) Jimmy Carter, the former U.S. President, 4) results announced by the National Electoral Council. All of these details, so smoothly integrated into the text, generate an air of authenticity, telling the reader that the writer really knows what he is talking about. 


\section{CURRENT HOMEWORK}

Some years ago, I was asked to write a number of case histories for one of my industrial clients. The final work would be compiled into a hardbound book for presentation to clients-especially prospective clients. For this, two very specific requirements had to be meet:

1. The company had a highly diversified range of professional products and services. Therefore, potential readers would not necessarily understand or even be interested in many of the case histories. It would thus be necessary to write the histories in such a way that they would attract the attention of potential readers who had no direct relationship with or understanding of the technical field each case would cover.

2. The case histories had to be as short as possible, because my client wanted the book to be colorfully illustrated, with text covering no more than a single page in each doublepate spread.

This was indeed quite a challenge.

To meet the first requirement, we decided each text had to begin by putting the case history into a broad cultural, historical, or philosophical context potentially of interest to all readers, then move on to the special expertise my client brought to the project. To meet the second criterion, each text would have to be as short as possible, while at the same time clearly explaining any technical aspects of the project with which the wide range of potential readers might not be familiar.

I told my client writing a rigorously short text like this is much more difficult and timeconsuming than writing a flabbily structured longer one. Indeed, if successful, the final text might appear to be self-evident, almost as if it had written itself. I had to strongly make this point to justify my fee, which otherwise might have seemed outrageous. So I showed them the process.

Here is the development of one of the case histories. The first draft was aimed essentially at digesting the background material and putting it into some kind of coherent form, i.e. "talking the text." I then wrote a shorter, more tightly structured second draft. Finally, I wrote a third draft to make the text as short as possible.

Below you will see the three-stage development of one of these case histories. You will then be asked to develop a second case history on your own. As you work, bear in mind the objective of this homework assignment is help you experience and remember two of the most important writing lessons you will ever learn.

Lesson 1: The most impressive thing about a well-written text is that it seems so unimpressive. 
Lesson 2: Ensure that the people who have to review and approve your work fully understand why a well-written text seems so unimpressive.

Failure to properly educate your critics means your work will not be properly valued. If you are a consultant like me, in turn this means you just might not get paid!

\section{Sample Case History}

Editor's Note: The names of the companies in the following text are fictitious. Enterprises $X$ refers to the contracting company that carried out the project described. Engineering Solutions $Y$ refers to my client.

\section{Draft 1 (462 words)}

People who attend concerts are rightly impressed by the talent and skill of the performers, the stage setting, and perhaps even the architecture and decoration of the concert hall. However, it is generally only specialists, including the performers themselves, who recognize and appreciate the incredible hidden technology that makes it all possible.

The Concertgebouw, inaugurated in 2002 in Bruges, Belgium, when this historic city was the European capital of culture, is a case in point. For example, the concert hall is fitted with movable ceilings and special curtains to ensure the best acoustics for any type of performance. Moreover, the building rests on several thousand springs to ensure that the acoustics are not damaged by vibrations from outside.

Last, but certainly not least, the orchestra zone at the front part of the stage can be raised or lowered according to need, i.e. to become part of the stage, to serve as an orchestra pit, to provide additional places for the audience, etc. It can also be used to raise or return stage equipment from the basement.

To carry out its multiple tasks, the Concertgebouw's orchestra zone consists of two individually controlled lifting platforms 16 meters wide, situated one behind the other. One platform has a depth of 3 meters and the other a depth of 1.5 meters. Each one rests on six cylindrical elevators with spiral grooves going around them from top to bottom that are pushed upwards by a sliding metallic band situated between the grooves. Thanks to the grooves, the band is maintained vertically between the cylindrical elevators that it separates.

This ingenious arrangement means that the in the down position it is especially compact. The spiral is retracted on itself and the band is wrapped around a separate bobbin, which eliminates the need for extra space under the stage to house the drive mechanism. The control panel and protection are crucial because in case of incorrect use, the band could become dislodged from the grooves and destabilize the whole system.

The elevators under each lifting platform are controlled by a single motor whose movement is transmitted by chains. This mechanism guarantees synchronization of the six elevators. With 
previous installations, there was always a risk of the system unexpectedly blocking, with disastrous consequences for any show that might be then going on.

Designing and installing the new system was entrusted to Enterprises $X$, an industrial installation company located in nearby Vlaamsville. Enterprises $X$ in turn chose an ILC (intelligent logic controller) from Engineering Solutions $Y$. The operational security of the installation is assured by SafetyBridge, a configurable and flexible system also from Engineering Solutions $Y$. "We frequently use Engineering Solutions $Y$ components because we are well satisfied with their prices and functionality," says I.M. Anonymous, an Enterprises X software engineer.

\section{Draft 2 (382 words)}

People who attend live shows are rightly impressed by the talent and skill of the performers, the lighting, the decor, etc. However, they are seldom aware of the incredible hidden technology that makes it all possible.

For example, the magnificent Concertgebouw in Bruges (Belgium) is fitted with movable ceilings and special curtains to ensure the best acoustics for any type of performance. Moreover, the building rests on several thousand springs to ensure that the acoustics are not damaged by vibrations from outside.

Especially impressive is the movable the orchestra zone at the front part of the stage, which can be raised or lowered according to need, i.e. to become part of the stage, to serve as an orchestra pit, to provide additional places for the audience, etc. It can also be used to raise or return stage equipment to and from the basement.

The Concertgebouw's extremely utilitarian orchestra zone consists of two individually controlled lifting platforms, 16 meters wide and situated one behind the other. Each platform rests on six cylindrical elevators with spiral grooves going around them from top to bottom that are moved upwards and downwards by a sliding metallic band situated between the grooves. The grooves ensure that the band is maintained vertically between the cylindrical elevators that it separates.

This ingenious arrangement means that the spiral is retracted on itself and the band is wrapped around a separate bobbin, eliminating the need for extra space under the stage to house the drive mechanism.

The elevators under each lifting platform are controlled by a single motor whose movement is transmitted by chains. This guarantees synchronization of the six elevators. Previous installations always carried a risk of the system unexpectedly blocking and disrupting any performance in progress.

The Concertgebouw entrusted designing and installation of the new system to Enterprises $X$, an industrial installation company located in nearby Vlaamsville. Enterprises $\mathrm{X}$ in turn chose an ILC 
(intelligent logic controller) from Engineering Solutions Y. The operational security of the installation is assured by SafetyBridge, a configurable and flexible system also from Engineering Solutions Y. Since being installed in 2002; the system has more than met expectations.

"We frequently use Engineering Solutions $Y$ components because we are well satisfied with their prices and functionality," says I.M. Anonymous, an Enterprises $X$ software engineer.

\section{Draft 3 (298 words)}

The magnificent Concertgebouw in Bruges, Belgium, is a treasury of theatrical technology to help the performers perform and the audience to get the most enjoyment from the performances. For example, its movable ceilings and special curtains ensure the best acoustics for any type of performance, as do the several thousand springs under the building that damp down outside vibrations.

Especially impressive is the movable the orchestra zone. Located at the front of the stage, it can be raised or lowered according to need, i.e. extend the stage, provide an orchestra pit, raise or lower stage equipment to and from the basement, etc.

The zone consists of two 16 meters wide lifting platforms situated one behind the other. Each rests on six cylindrical elevators surrounded by spiral grooves. The platforms are moved up and down by a sliding metallic band situated between the grooves. In their lowest position, each spiral retracts on itself and the band is wrapped around a separate bobbin, eliminating the need for extra space under the stage to house the drive mechanism.

All the elevators are controlled by a single motor to guarantee their perfect synchronization. Less sophisticated installations risk unexpected blocking, thus disrupting any performance taking place on stage.

The Concertgebouw entrusted the design and installation of the new system to Enterprises $X$, an industrial installation company located in nearby Vlaamsville. Enterprises $X$ in turn chose an ILC (intelligent logic controller) from Engineering Solutions Y. For maximum operational security, the installation is under the constant scrutiny of SafetyBridge, a configurable and flexible system also from Engineering Solutions Y. Since being installed in 2002, the installation has exceeded expectations.

"We frequently use Engineering Solutions $Y$ components because we are well satisfied with their prices and functionality," says I.M. Anonymous, an Enterprises $\mathrm{X}$ software engineer.

Now it's your turn. 
Here is the first draft of another case history for the same client. See if you can write a second draft that is significantly shorter while maintaining the tone, style, and all the important information of the first. Then see if you can write a third draft that is even shorter.

\section{Draft 1 (321 words)}

Managing a railroad infrastructure has many parallels with managing a fine restaurant or a topclass hotel. Users should hardly be aware that you are there except on rare occasions when something goes wrong. And then only for the briefest amount of time needed to put it right!

However, managing a railroad infrastructure has another major concern-safety. Rail passengers have a right to expect that their train journey will be uneventful, getting them to their destination on time, and as smoothly and as comfortably as possible. With the increasing amount of rail traffic and the increasing speeds of trains, the safety aspect daily takes on ever more significance.

This is why when Infrabel, the division of the Belgian national railway charged with managing the country's rail infrastructure, decided to centralize signaling as part its attempt to upgrade reliability and safety, it turned to Enterprises $X$ (Lummen, Belgium), a recognized leader in such work. Enterprises $\mathrm{X}$ then chose to use components supplied by Engineering Solutions $\mathrm{Y}$.

The signaling upgrade is part of the Belgian railways' attempt to develop an integrated European Railway Traffic Management System. The contract with Enterprises X is worth 10 million euros over five years. "The tendering criteria were particularly strict," says I.M. Anonymous, Senior Sales Engineer at Enterprises X. "Five of our staff worked for four weeks on a turnkey technical-commercial proposal."

Ensuring easy, cost-effective installation and system reliability required components of impeccable quality and a close relationship with the component supplier, which is why Enterprises $X$ turned to Engineering Solutions $Y$. "We have worked with Engineering Solutions $Y$ for many years now. Their products are of a very high standard, readily available and the working relationship is always efficient," says I.M. Anonymous.

Moreover, Engineering Solutions $Y$ components are particularly suitable for use in harsh and industrial environment due to their resistance to vibration. This is crucial next to railway tracks where trains powerful trains constantly go thundering by.

\section{About the Author}

Philip Yaffe was born in Boston, Massachusetts, in 1942 and grew up in Los Angeles, where he graduated from the University of California with a degree in mathematics and physics. In his 
senior year, he was also editor-in-chief of the Daily Bruin, UCLA's daily student newspaper. He has more than 40 years of experience in journalism and international marketing communication. At various points in his career, he has been a teacher of journalism, a reporter/feature writer with The Wall Street Journal, an account executive with a major international press relations agency, European marketing communication director with two major international companies, and a founding partner of a specialized marketing communication agency in Brussels, Belgium, where he has lived since 1974. He is the author of more than 20 books, which can be found easily in Amazon Kindle.

DOI: $10.1145 / 3209658$ 